Chapter 3

\title{
Immunological Mechanisms and Clinical Aspects in Pulmonary-Renal Syndrome: A Review
}

\author{
N. Lukán \\ Additional information is available at the end of the chapter \\ http://dx.doi.org/10.5772/55181
}

\section{Introduction}

McGraw-Hill Concise Dictionary of Modern Medicine [1] defines pulmonary-renal syndrome (PRS) as an idiopathic condition characterized by pulmonary hemorrhage, rapid progressive glomerulonephritis, and positive autoantibodies. Pulmonary-renal syndrome may be also defined as a heterogeneous group of multisystem diseases - e.g. Goodpasture syndrome, Wegener's granulomatosis, collagen vascular disease - in particular systemic lupus erythematosus, polyarteritis nodosa, Henoch-Schönlein purpura, and various other conditions, which all have prominent pulmonary and renal components. According to Sanders [2] the strict definition of pulmonary-renal syndrome is the combined clinical picture of rapid progressive glomerulonephritis and pulmonary capillaritis requiring histological confirmation.

If we translate the definition into pathological nomenclature, pulmonary-renal syndrome is defined as combination of diffuse alveolar hemorrhage (DAH) and immune crescent glomerulonephritis. The essential substrate of all these changes is vasculitis, which is according to contemporary nomenclature based mostly on morphological and histopathological criteria. These criteria for the most common forms of vasculitides were introduced in 1994 by Jennette et al. at the Chapel Hill Consensus Conference organized by the American College of Rheumatology [3]. The inflammation of small vessels (microangiopathic vasculitis) restricts blood flow to various organs and damages them. If correct diagnosis and appropriate treatment are delayed the condition can be fatal. Prognosis is good when treatment begins before onset of respiratory and renal failure. Because of the similarity in clinical picture, differential diagnosis of these diseases at the bedside can be challenging.

The pathophysiology of the vasculitides is based on immunologic mechanisms. These appear to play an active role in mediating the inflammatory response, but their exact mechanisms still 
remain poorly understood. Although the primary events that initiate this process remain largely unknown, recent investigations have brought us closer to understanding some of the critical pathways involved in disease and provided a rationale for the study of novel therapeutic agents [4].

\section{Historical sense of the term "pulmonary - renal syndrome"}

The first mention on pulmonary-renal syndrome is dated to year 1919 when the „father of viral pathology" in the United States Dr. Ernest William Goodpasture (1886 - 1960) published his work "The Significance of Certain Pulmonary Lesions in Relation to the Etiology of Influenza in American Journal of the Medical Sciences [5]. He described two cases from more than fifty autopsies where in patients dying in the great flu pandemic (Spanish flu) no bacterial etiology was confirmed. In one of the two patients massive alveolar hemorrhage and fulminant glomerulonephritis were present. It was never discovered what underlying disease other than influenza this patient may have had. Human influenza virus was described fourteen years later by Laidlaw and coworkers [6]. In 1958 two Australian scientists Stanton and Tange in the discussion of their paper analyzed Goodpasture's old finding and associated pulmonary hemorrhage with glomerulonephritis with the name of Dr. Goodpasture, as Goodpasture syndrome [7]. According to the biography written by Collins (2010), E. Goodpasture did not approve the association of his name with this syndrome [8]. In 1967 the discovery of anti-GBM antibodies were associated with Goodpasture nephritis [9].

At present pulmonary-renal syndrome broadened the family of diseases, where diffuse alveolar hemorrhage and immune crescent glomerulonephritis are participating. Therefore, it is not possible to say only glomerular basement membrane (Goodpasture) disease means pulmonary-renal syndrome. The term pulmonary-renal syndrome should be associated with the term pulmonary-renal vasculitic syndromes [10].

\section{Histopathology}

Pathological expressions of vasculitis are not usually specific for a particular diagnostic category of vasculitis. The primary pathology in the majority of pulmonary-renal syndrome is inflammation and necrosis of vessel wall classified according to the Chapel Hill Consensus Conference classification [3] as medium/small vessel vasculitis. Generally, inflammation affects arterioles, capillaries and venules with two basic types of necrosis - fibrinoid and granulomatous. In the very early stage of inflammation there is a massive influx of polymorphonuclear leukocytes and monocytes accumulating in the capillary space. Later the condition is accompanied by proteinacousexudate. Damage of the capillaries and disruption of basal membranes with leakage of erythrocytes is followed by an influx of macrophages. Fibrinoid depositions cause the formation of extracapillary (crescent) cell proliferation in the glomerulus [11]. Changes in lungs give rise to isolated necrotic pulmonary capillaritis where damaged red blood cells migrate directly into alveolar tissue resulting in alveolar haemorrhage [12]. 
Jennette et al. [13] described pathologic features of different necrotizing vasculitis types indicating various pathogenic mechanisms causing the injury. In anti-GBM disease or immune complex disease the pathogenic complexes between antibodies and antigens are located exclusively or predominantly in vessel walls. In patients with ANCA vasculitis, these autoantibodies are in the interstitial fluid and also in the blood. ANCA activate neutrophils and monocytes in blood vessels, as well as in interstitial tissue. Activation in the vessels causes necrotizing vasculitis and activation in the tissues necrotizing tissue inflammation. Clinical association of dominating organs in pulmonary-renal syndrome is shown in table 1.

\begin{tabular}{lcccc}
\hline Organ & MPA & GPA (WG) & CSS & GPS \\
\hline Kidney & 90 & 80 & 45 & 75 \\
\hline Lung & 50 & 90 & 70 & 60 \\
\hline
\end{tabular}

Table 1. Approximate frequency of organ system involvement (\%)

Interstitial inflammation is accompanied by capillary trombosis, disintegration of blood vessel wall, loss of integrity of tissue structures, epithelial cell hyperplasia, accumulation of red cells (and later hemosiderin), depositions of proteins (immunoglobulins, immune-complex proteins), interstitial fibrosis and atrophy. The actual picture is dependent on different organ structure of lungs and kidneys, as well as on primary stimulus.

Presence of specific granulomatous inflammation is typical for granulomatosis with polyangiitis (GPA, formerly Wegener's granulomatosis) described and defined by Wegener in 1939 [14] and Former in 1950 [15] respectively. Morphological detected recruitment of inflammatory cells, as well as immune competent cells (T-cells, B, cells, macrophages) and sometimes also giant-cells are confirmed by immunostaining of autoantibodies, detection of cytokine release and oxygen-free radical formation.

Pulmonary-renal syndrome has a wide spectrum of organ histopathological changes. Severe renal vascular damage can be accomapnied by absent or mild pulmonary changes. On the other hand severe pulmonary injury can be followed by mild renal destruction or normal renal histology.

\subsection{Renal pathology}

Renal pathology is expressed by various forms of glomerulonephritis (anti-GBM, immunocomplex, necrotizing pauci-immune). In rare cases sequential development supposed to be of pathogenic importance: injury caused by ANCA may uncover the Goodpasture antigen. The concept that only one antigen may trigger another one requires further support [16].

Immunohistochemical classification of renal capillary vasculitides [17] based on renal biopsies is characterized by the presence of:

1. anti GBM antibodies - type I crescentic GN

2. immune complexes - type II crescentic GN 
3. pauci-immune ( only circulating ANCA) - type III crescentic GN

\subsection{Pulmonary pathology}

The underlying pulmonary lesions (necrotic pulmonary capillaritis) are clinically expressed as diffuse alveolar haemorrhage. Disruption and degradation of the pulmonary capillary wall and interstitial matrix results in vessel wall destruction and necrosis. Cordier and Cottin [18] found capillaritis as the most common pathological finding $(60 \%)$ in ANCA-related vasculitides with pulmonary complications. However, capillaritis was not observed in all patients. It is likely that vessel inflammations may be overlooked in some cases if not specifically searched [19].

According to recommendations of Jennette and Falk [20] an accurate precise clinical diagnosis usually requires the integration of many different types of data, including clinical signs and symptoms, associated diseases, histological pattern of inflammation (eg, granulomatous versus necrotizing), immunopathological features (e.g. presence and composition of vascular immunoglobulin deposits), and serological findings (cryoglobulins, hypocomplementemia, hepatitis B antibodies, hepatitis C antibodies, ANCAs, anti-GBM antibodies, ANA). Specific diagnosis of a vasculitis is very important because the prognosis and appropriate therapy vary substantially among different types of vasculitis. Many attempts to re-evaluate and to refine the present nomenclature of vasculitis were done, however the complexity of vasculitic syndromes, as well as of pulmonary-renal syndrome complicates not only the estimation of appropriate diagnosis, differential diagnosis but also hampers effective treatment.

\section{Immunopathogenesis}

Potentially accepted immunopathological mechanisms of pulmonary-renal syndrome involve antiglomerular basement membrane antibodies, antineutrophil cytoplasm antibodies, generation of immunocomplexes, activation of complement and haemocoagulation. Due to different pathogenesis of pulmonary-renal syndrome in various clinical diagnoses, common immunopathological features (except systemic inflammation) could not be specified. As seen in most inflammatory diseases, the systemic response to insult may be as important as the initial stimulus.

\subsection{Genetical and environmental influence}

The current understanding of autoimmune disorders suggests that some environmental factors initiate disease in a genetically susceptible individual. The importance of genetic factors, especially the genes of major histocompatibility complex has been increasingly recognized in determining susceptibility to autoimmune diseases. Because of the low incidence of all nosological entities of pulmonary-renal syndrome, it is not possible to examine the inheritance of genes within affected families predisposing to this disease.

In pulmonary-renal syndrome, as in most autoimmune disorders, the precise initiating events are not known. Exposure to hydrocarbons is known to cause damage to pulmonary/renal 
endothelial cells and so could expose components of the alveolar basement membrane to cells of the immune system, initiating an immune response [21]. The induction of vasculitis seems multifactorial, with interplay of environmental factors and genetic predisposition creating the environment for development of disease [22].

\subsection{Kidney-lung crosstalk}

New experimental data haveemerged in recent years focusing on theinteractiveeffects of kidney and lung dysfunction, and these studies have highlighted the pathophysiological importance of proinflammatory and other immunologic pathways as well as the complex nature of interorgan crosstalk. Because pulmonary and renal dysfunction frequently coexist, the effects of failure of either organ are particularly relevant to the function of the other. Evidence suggests that deleterious kidney-lung interactions or crosstalk rise, at least in part, due to the loss of the normal balance of immune, inflammatory and soluble mediator metabolism. These processes occur after severe insults and cause induction of organ injury [23]. Organ crosstalk is a consequence of both directloss of normal function and inflammatory dysregulation resulting from both organ failure. Cellular (e.g. neutrophils) as well as soluble mediators (cytokines) contribute to the inflammatory dysregulation under these circumstances [24].

\subsection{Immunology of inflammation}

Interactions between inflammatory cells and damaged endothelium end in vessel inflammation (vasculitis), the major manifestation of all clinical entities. Cytokines, chemokines (such as IL-8) complement components, circulating immune complexes, and antibodies can be primary determinants of initiators of endothelial cell damage. When focusing on two basic clinical representatives - Goodpasture disease and granulomatosis with polyangiitis, damage of the vessel wall of glomeruli and alveolar capillaries are caused by antigen-stimulated white blood cells, anti-GBM antibodies and ANCA, respectively. In antiGBM and ANCA vasculitis, the pathologic finding of focal, lytic necrotizing injury suggests highly effective local activation of neutrophils and monocytes with release of oxidants and proteases that are neutralized beyond the site of injury [13].

Concurrent ANCA and anti-GBM antibody production can be seen in selected patients, but reasonable explanation is unknown. It is possible that ANCA-related proteases damage or expose the nephritogenic epitopes in cr3 (IV) collagen in GBM, and this in turn leads to antiGBM antibody production. It is unlikely that the crossreactivity between p-ANCA and antiGBM antibodies is derived from the same autoantibody repertoire, because there does not appear to be a structural relationship between c-ANCA and a3 (IV) NC I collagen [25]. It is currently unclear whether there is any structural cross-reactivity between c-ANCA and antiGBM antibodies [26].

\subsection{Cellular and humoral mechanisms}

Immunological mechanisms involved in initiation and prolongation of inflammatory state could be divided to two groups: cellular mechanisms (activity of immune-competent cells) and 
humoral mechanisms (proteins, mediators). Inflammation is tightly connected also to oxidative stress either through increased formation of ROS and/or the decreased activity of antioxidant systems.

It should be postulated in the view of common association in all disease entities that the damage is caused by free radical formation of injured tissues. Local release of inflammatory cytokines and chemokines further activate endothelial cells to upregulate soluble adhesion molecules, enhanced activation of neutrophils and generation of reactive oxygen species which serve to amplify the initial inflammation leading to dysregulated apoptosis, secondary necrosis and overt vascular injury.

The immune system may target the tissues due to structural alterations in proteins or cell surfaces. Finally, the production of necessary anti-inflammatory factors may be impaired after hypoxia. Initiating signals - triggers of inflammation can activate the inflammatory process by several mechanisms that may occur simultaneously [27]:

1. Passively released factors from injured or exposed cells due to breakdown of cellular barriers.

2. Stress or injury (hypoxia) can induce the active synthesis of pro-inflammatory signals.

3. Immune system receptors (cellular, humoral) may recognize altered or exposed surface structures.

4. Damaged cells have decreased expression of inhibitory (anti-inflammatory) factors permitting uncontrolled activation of inflammatory cells or systems.

Binding of ANCA to neutrophil membranes activates the cells leading to the release of lytic enzymes, chemoatractant interleukin- 8 and oxygen free radicals. Neutrophils subsequently aggregate on endothelium causing inflammation and damage to the vasculature. Still, it remains unclear in many diseases whether or not ANCAs are simply playing a bystander role in the inflammatory cascade or directly driving vasculitic inflammation [28].

Gröne [29] describes except of the role of ANCAs, other immunopathogenetic factors important in vasculitides. They include innate immunity factors, transcription factors such as NFkB, endothelial cytoprotective agents such as NO. In summary:

1. ANCA may be directed against several antigens, in the majority of cases against proteinase- 3 and myeloperoxidase. The complex of proteinase- 3 and ANCA leads to an increased expression of CD14, CD18 and an elevated synthesis of cytokines and chemokines such as interleukin 1, interleukin 8 in monocytes. In addition granulocytes generate reactive oxygen species, ANCA may also bind to a surface glycoprotein (gp130) expressed on glomerular and peritubular endothelia in the kidney. Thus the activation of granulocytes, monocytes and endothelial cells by ANCA may be a critical step in the initiation phases of vasculitis, ultimately leading to apoptosis.

2. NO is cytoprotective for endothelial cells in low concentrations.

3. The transcription factor complex NFkB is a key regulatory transcription factor for the expression of genes and proteins associated with acute inflammatory processes and 
"endothelialitis". Inhibition of NFkB activity by a decoy-oligonucleotide prevented activation of endothelial cells in reperfusion injury and vascular rejection.

4. The complement system probably plays an essential role in the initiation and propagation phases of vasculitis. Specifically the pneumococcal C-polysaccharide-reactive protein (CRP), synthesized after trauma and infection, can potently activate the complement cascade leading to activation of endothelial cells with increased expression of adhesion molecules.

Above mentioned pathogenetic mechanisms of vasculitides seem to be important and common factors for the generation and maintenance of vascular inflammation; nevertheless these factors are only part of the spectrum of different humoral and cellular responses in vasculitis [29].

\subsection{Ischemic/reperfusion injury}

Acute onset of severe pulmonary-renal syndrome is closely connected with ischemiareperfusion injury when both innate and adaptive immunity contribute to their pathogenesis. Kidney resident cells promote inflammation after ischemic/reperfusion injury by increasing endothelial cell adhesion molecule expression and vascular permeability. Kidney epithelial cells bind complement and express toll-like receptors and resident and infiltrating cells produce cytokines/chemokines. Early activation of kidney dendritic cells initiates a cascade of events leading to accumulation of interferon- $\gamma$-producing neutrophils, infiltrating macrophages, CD4+ T cells, B cells and invariant natural killer T cells. Bajwa et al. [30] recently implicated the IL23/IL17 pathway in kidney ischemic/reperfusion injury, as well as the importance that T-regulatory cells can directly suppress the early innate inflammation, induced by ischemia/reperfusion, in an IL-10 dependent manner. Following the initial early phase of inflammation, the late phase involves infiltration of anti-inflammatory cells including regulatory $\mathrm{T}$ cells, alternatively activated macrophages and stem cells leading to attenuation of inflammation and initiation of repair.

\subsection{TNFalfa - proinflammatory cytokine}

Another possible connection between kidney and lung inflammation as a part of the systemic inflammatory pathway describe Campanholle et al. [31]. They concluded that pro-inflammatory mediators, TNF-alfa, IL-1 $\beta$ and MCP-1, released by the ischemic kidney might reach thelungs, induce inflammation, up-regulate COX-2 and iNOS expressions, and ultimately contribute to the accumulation and to activation of neutrophils and mononuclear cells.

TNF-alpha, a potent pro-inflammatory cytokine belongs to the group of mediators that activate leukocytes and endothelial cells. Neutrophils, other leukocytes, and platelets adhere via cognate receptors to the pulmonary endothelium. Activated neutrophils release proteases, leukotrienes, reactive oxygen intermediates, and other inflammatory molecules that amplify the inflammatory response. ROS and proteases can directly damage alveolar-capillary membrane integrity [32]. On the other side the lectin-like domain of TNF-alpha has positive effects on permeability of the epithelial-endothelial barrier in the lungs. This domain is able 
to blunt ROS production in pulmonary artery endothelial cells under hypoxia and reoxygenation, and reduce ROS content in inflammatory conditions [33].

TNF-alpha - an important cytokine involved in pathogenesis of inflammation, is an example of a "moonlighting protein", with differential activities mediated by its receptor-binding versus its lectin-like domains, which opens the possibility to design and develop more sophisticated therapeutic regimens for patients with increased permeability of the epithelialendothelial barrier of the lung, which in pulmonary-renal syndrome can occur. However, in the future, more research is needed in order to reveal the underlying mechanisms of TNF's protective versus deleterious effects [34].

\subsection{Reactive oxygen species and nitric oxide engagement}

Among enzymes incorporated in the free radical formation, eNOS (NOS3) has been shown to inhibit vascular inflammation in many different model systems, but its role in the pathogenesis of vasculitis has not been elucidated yet. According to Schoeb et al. [35] eNOS serves as a negative regulator of vasculitis in experimental (mice) model of pulmonary-renal syndrome and they further suggest that nitric oxide produced by this enzyme may be critical for inhibiting lesion formation and vascular damage in human vasculitides. Derangements in the key oxidative stress enzymes, nitric oxide synthase and heme oxygenase may also facilitate distant organ dysfunction. Disordered NO metabolism in the setting of inflammation is well established. While the cause of this dysregulation is not entirely clear, asymmetric dimethyarginine seems to play a significant role [36, 37]. Asymmetric dimethyarginine is an inhibitor of endothelial NO synthase and shifts NO metabolism toward production of oxygenbased free radicals [38]. MPO released from activated neutrophils are involved in the formation of NO-derived reactive oxygen species [39]. ROS produced by macrophages in combination with reactive nitrogen intermediates cause protein nitration in endothelial cells [40]. This could be related to activation of cytokines produced by macrophages to elicit proinflammatory and prothrombotic responses in endothelial cells [41]. MPO produces a highly deleterious reactive oxygen species, the hypochlorous acid $(\mathrm{HOCl})$. Anti-MPO antibodies from patients with small vessel vasculitis (MPA) can trigger the release of MPO by neutrophils and monocytes. AntiMPO antibodies can activate MPO to generate an oxidative stress deleterious for the endothelium.

Guilpain et al. [42] recently demonstrated that MPA sera with anti-MPO antibodies activated MPO in vitro, and generated free radicals (hypochlorous acid), whereas sera from MPA patients with no anti-MPO antibodies or healthy individuals did not. Free oxygen radical production and endothelial lysis were abrogated by N-acetylcysteine (NAC), an antioxidant molecule through the augmentation of glutathione biosynthesis. N-acetylcysteine significantly reduced the activation of myeloperoxidase and improved the survival of endothelial cells exposed to byproducts of myeloperoxidase activation. Thus, anti-MPO antibodies could play a pathogenic role in vivo by triggering an oxidative burst leading to severe endothelial damages. 
During early stage of human septic shock Spapen et al. [43] founded massive decrease of IL-8 after N-acetylcystein (NAC) administration. According to that finding, Park et al. [44] supposes another possible mechanism of NAC effect - through inhibition of IL-8.

In Goodpasture's syndrome normal exposure of epitopes by self-limited generation of ROS is not itself sufficient to launch a fatal autoimmune response. ROS can be produced in response to various normal stimuli such as mediators of inflammation, environmental toxins, de-novo respiratory bursts. Excessive ROS may influence GBM degradation by proteolytic enzymes [45]. Therefore, the presence of ROS in the microenvironment around the GBM can likely activate several pathways of protein modification in renal, as well as in pulmonary tissue in Goodpasture's syndrome. Kalluri et al. [46] suggest that ROS can alter the hexameric structure of type IV collagen to expose or destroy selectively immunologic epitopes embedded in basement membrane. The reasons for autoimmunity in Goodpasture syndrome may lie in an age-dependent deterioration in inhibitor function modulating oxidative damage to structural molecules. ROS therefore may play an important role in shaping post-translational epitope diversity or neoantigen formation in organ tissues.

\subsection{Natural antibodies}

Natural antibodies produced by B-cells may play a role in prevention of pathological autoimmune reactions by binding to microbial epitopes that are similar or identical to selfantigens [47].

Bacterial superantigens trigger the activation of autoreactive cells such as toxic shock syndrome toxin 1 and Staphylococcal enterotoxins. These superantigens are generally considered to be the triggers of exacerbation in Wegener's granulomatosis [48, 49].

\subsection{Role of Th 17}

Under certain conditions, T helper type cells can differentiate into regulatory $\mathrm{T}$ cells producing immunosuppressive cytokines such as transforming growth factor- $\$$ and IL-10. These regulatory $\mathrm{T}$ cells representing about $5 \%$ to $10 \%$ of CD4+ $\mathrm{T}$ cells in the steady state, play a central role in immune homeostasis and in preventing autoimmune diseases in general [50, 51]. Regulatory $\mathrm{T}$ cells exist naturally and are called natural regulatory $\mathrm{T}$ cells expressing CD25 and Foxp3. T cells can also convert into regulatory $\mathrm{T}$ cells upon certain antigen recognition and are called antigen-specific regulatory T cells that secrete IL-10 and/or transforming growth factor- $\beta$. Indeed, regulatory $\mathrm{T}$ cells are required to control infection-induced immunity in a host, including autoimmunity inhibition [52].

Recently discovered regulatory Th17-cells and cell-derived cytokines play an important role in the pathogenesis of several autoimmune/inflammatory diseases including vasculitides. In Wegener's granulomatosis, regulatory T-cells display impaired suppressor activity potentially favouring inflammation and break of tolerance [53]. Th17-cells produce several cytokines such as IL-17, IL-21, IL-22, CCL-20 which induce massive inflammatory tissue reactions and these cytokines also stimulate nonimmune cells (fibroblasts, endothelial and epithelial cells) to the production of proinflammatory mediators (IL-6, TNF-alfa, prostaglandins, NO, MMP and 
chemokines [54]. New results, showing the possibility that regulatory Th17 cells and corresponding cytokines (IL-17, IL-23) involved in the pathogenesis of GPS as well in WG might be used for the directed therapy of pulmonary-renal syndrome in the future.

Vasculitis (especially Wegener's granulomatosis) is associated with bacterial infection, in particular nasal occurence of Staphylococcus aureus. Infection may play a role in the induction of autoimmunity as well as in the effector phase of the disease. In this relation Tadema et al. [55] emphasize the role of innate immunity that is involved in the development of a Th17driven immune response, consistent with skewing towards a Th17 T cell phenotype that has been observed in Wegener's granulomatosis. Their findings shed new light on the potential role of $\gamma / \delta \mathrm{T}$ cells in host defense and inflammatory diseases, provide important new information on the pathogenic role of IL-23 and IL-1 $\beta$, and underline the importance of targeting these cytokines in the development of new therapeutic interventions against many autoimmune diseases.

Sutton et al. [56] demonstrated that $\gamma / \delta$ T cells activated by IL-1 $\beta$ and IL-23 are an important source of innate IL-17 and IL-21 and provide an alternative mechanism whereby IL-1 and IL-23 may mediate autoimmune inflammation.

In other study Ooi et al. [57] suggested the importance of IL-23, a key cytokine in the induction and maintenance of autoimmune responses, in Th1 responses that could play a rolein someforms of glomerulonephritis especially in anti-GBM (Goodpasture) disease. This experimental work emphasizes potential mechanisms in the treatment of several forms of glomerulonephritis.

Accumulating data from animal models support a role for Th17 cells and their cytokines in various autoimmune and inflammatory processes. Emerging data from running clinical trials indicate the importance of Th17 cells in such immunological processes, too. Future studies will allow us to evaluate the role of each cytokine independently in contributing to human diseases with immune-mediated pathologies and to design optimal cytokine-targeted therapies for these diseases [58].

\subsection{Perspectives of treatment - modulation of inflammation}

After careful analysis of numerous animal studies demonstrating the importance of inflammation in the pathogenesis of pulmonary-renal syndrome, as well as the clinical correlates demonstrating activation of the same systems in patients with systemic autoimmunity, there is a reason to hope that different modalities of anti-inflammatory treatment could ameliorate the course of the disease. The inflammatory process is however extremely complex due to its multifactorial etiology and considering also in the context of differences among systems [59]. For example renal failure involves complex host-kidney interactions in which the inflammatory state of the host contributes to the development of renal failure and injury of the inflamed tissue further modulates the inflammatory state of the host. One of the greatest obstacles to effective treatment is establishing the diagnosis as early as possible based on all available diagnostic procedures, including invasive ones. Earlier and more reliable identification of clinical signs and laboratory markershasbecomeanimportant toolin relation toestablisheffective treatmentmodalities. Once the inflammatory response has been set in motion, treatment may be ineffective and could 
conceivably delay recovery. Strategies that prevent the initiation of inflammation by targeting the earliest signals or recognition of the injured tissue may be of particular therapeutic benefit in these conditions [25].

\section{Semi-systemic (pathologic/clinical) classification}

The etiology of pulmonary-renal syndrome could be associated with variety of diseases. A possible classification based on clinical symptomatology and histopathology is described in Table 2.

\begin{tabular}{|c|c|}
\hline & Etiology of pulmonary-renal syndrome \\
\hline Cause & Disease \\
\hline \multirow{6}{*}{ Systemic vasculitides } & Wegener's granulomatosis \\
\hline & Churg-Strauss syndrome \\
\hline & Cryoglobulinemia \\
\hline & Henoch-Schönlein purpura \\
\hline & Behçet's syndrome \\
\hline & Microscopic polyarteritis \\
\hline \multirow{6}{*}{ Connective tissue disorders } & Polymyositis or dermatomyositis \\
\hline & Progressive systemic sclerosis \\
\hline & RA \\
\hline & SLE \\
\hline & MCTD \\
\hline & "Catastrophic" APS \\
\hline \multirow{4}{*}{ Renal disorders } & Goodpasture's disease \\
\hline & Idiopathic immune complex glomerulonephritis \\
\hline & IgA nephropathy \\
\hline & Rapidly progressive glomerulonephritis with heart failure \\
\hline \multirow{6}{*}{ Other } & Drugs (D-penicillamine, propylthiouracil, carbimazole, cocaine, ...) \\
\hline & Post-renal transplation failure \\
\hline & Idiopathic pulmonary-renal syndrome \\
\hline & Infection \\
\hline & Coagulopathy \\
\hline & Heart failure \\
\hline
\end{tabular}

Table 2. Etiology of pulmonary-renal syndrome

\section{Clinical involvement}

It is very important to establish an early diagnosis based on clinical vigilance, contemporary diagnostic laboratory support (immunology and biopsy) for the pulmonary-renal syndrome 
in order to avoid the severe consequences of rapid and irreversible loss of renal function or from severe pulmonary hemorrhage. Both can be avoided by appropriate initial immunosuppressive treatment [60]. In pulmonary-renal syndrome better understanding of interorgancrosstalk is of utmost importance, as current clinical care is many times limited to preventive and supportive measures [24].

In main clinical entities (Goodpasture's disease, ANCA associated vasculitis, SLE-associated vasculitis) induction and maintenance immunosupression is achieved by steroids and cyclophosphamide. Intensive plasma exchange to remove pathological antibodies, proinflammatory cytokines, complement compounds and factors of coagulation from circulation is beneficial for patients with pulmonary hemorrhage and severe kidney disease. Except of antibody removal, plasma exchange may have also other immunoregulatory effects and could potentiate the effects of immunosuppressive drugs [61]. Exchange procedures have beneficial effect on long-term renal recovery [62, 63]. Severe renal function impairment requires haemodialysis and progression to end stage renal failure renal replacement therapy is required [17]. In case of inevitable ICU admission supportive care is important as well.

During immunosuppressive regimes nosocomial infection used to be a common complication associated with high mortality [64]. Therefore minimizing the risk of infection has the highest of high priority. Patients with pulmonary-renal syndrome are often hypotensive because of a combination of dehydration, haemorrhage and systemic inflammatory response and may therefore require inotropic support [28]. Endotracheal intubation, tracheostomy, lung protective ventilation, transfusion and anticoagulation may be also necessary.

Antioxidant effect of $\mathrm{N}$-acetylcystein published by Fernández-Fernández and Sesma [65] in one patient with WG and also our unpublished experience suggests clinical improvement of systemic inflammation. Administration of NAC is based on two significant studies: the IFIGENIA trial in 2005 [66] (Idiopathic Pulmonary Fibrosis International Group Exploring Nacetylcysteine I Annual study) and the study by Guilpain et al. [42]. Both studies have reported that NAC significantly reduced the activation of MPO and improved the survival of endothelial cells. In a recent experimental study by Lee et al. [67] continuous infusion of NAC attenuated inflammatory response and acute lung and kidney injury after hemorrhagic shock in rats. This result supports the clinical experience.

Some recent studies are focused on anti-TNF molecules, anti-B-cells blockers [68], anti-BlyS [69], anti-IL5 molecules [70], antithymocyte globulin [71], blockers of costimulatory molecules [72], tyrosine-kinase inhibitors [73] and proteasome inhibitors [74]. The results of these studies are sometimes controversial but there is a real hope that they will provide useful knowledge in the near future.

Many questions still remain unanswered also in the use of intravenous immunoglobulins (IVIG). Such treatment should be considered as an effective regimen in many "off label" indications particularly in cases where standard immunosuppressive regimes fail or could be harmful. Despite some evidence of efficacy, dosage and timing of IVIG therapy, as well as the question of its costs/benefit ratio still remain insufficiently documented and controlled trials with definitive conclusions for clinical indications are needed. 
The basic immunomodulatory mechanisms of IVIG in autoimmune and inflammatory diseases are twofold. One is its action on humoral immunity and the second involves mechanisms of cell-mediated immunity. Both mechanisms interdependently involve modulation of expression and function of Fc receptors, interference with complement activation and the cytokine network, provision of antiidiotypic antibodies, modulation of dendritic cells, $\mathrm{T}$ and B-cell activation and differentiation and their effector functions [75]. Analogous to normal circulating immunoglobulins intravenous immunoglobulins have also anti-inflammatory properties modulating systemic inflammation during various inflammatory states.

According to BSR guidelines [76] IVIG may be considered as an alternative therapy in patients with refractory disease or in patients for whom conventional therapy is contraindicated, for example, in the presence of infection, in severely ill patients or in pregnancy (grade of recommendation B). In the management of refractory vasculitis it is important to identify causes of the vasculitis, such as, intercurrent infection or malignancy. In many European countries use of IVIG is limited for treatment of primary immune deficiencies where such treatment has been known to be life saving. Even though use of intravenous immunoglobulins in inflammatory diseases has been increased and a recent literature search revealed more than 150 off-label usages of IVIG, which included 6781 patients in clinical trials and 362 patients in case reports [77].

Until present immunological mechanisms of immunomodulatory effect of IVIG are not clearly known. In such context a question of adequate dosage appears in the relation of cost/benefits of unlabeled treatment. It is supposed that patients who respond to high-dose IVIG therapy would probably also respond to much lower doses, in many rheumatological indications vasculitides not excluded. In addition to economic reasons, low-dose regimen would likely help to reduce treatment related side effects. The lack of validated and generally accepted outcome measures as well as prospective clinical studies makes it difficult to compare the effect of different interventions in different cases [78].

\section{Conclusions}

Pulmonary-renal syndrome is a complex and heterogenous clinical picture involving rapid progressive glomerulonephritis and pulmonary capillaritis based on inflammation and necrosis of vessel wall. Morphological changes of pulmonary-renal syndrome are consequences of immunologically mediated processes and the unconctrolled derangement of the immune system could cause multiorgan dysfunction and fatal outcome.

The diagnostic procedure should focus on recognizing the earliest phases of the initiation and progression of the inflammation through a reliable panel of immunological and organ specific functional markers. In the near future novel diagnostic tools should be introduced in the diagnosis and differential diagnosis of pulmonary-renal syndrome, including gene expression profiles, cytokine profiles, markers of oxidative stress and many others.

Traditional clinical approach to treat pulmonary-renal syndrome was divided among rheumatologists, nephrologist and pneumologists but the improving knowledge of its 
pathogenesis clearly indicates the need of an interdisciplinary team work incorporating intensive care specialists and immunologists as well. This integrative approach could pave the way toward the introduction of more efficient novel treatment regimes. Another challenge is the high risk of relapses in these condition occurring up to $50 \%$, of the patients. Early establishment of the exact diagnosis and effective etiology oriented treatment in such cases is rather difficult task requiring further experimental and clinical research and cooperation of different specialists.

Perspective therapeutic approaches based on contemporary immunological knowledge (B-cell depletion, costimulatory molecule blockers, siRNAs controlling intracellular processes, cytokine treatment) supported by clinical experience will bring benefits for induction and maintenance of remission or also excluding the menacing catastrophic scenario of the disease.

\title{
Abbreviations
}

ANCA - anti-neutrophil cytoplasmic antibody, APS - antiphospholipid syndrome, CSS Churg-Strauss syndrome, DAH - diffuse alveolar hemorrhage, GBM - glomerular basement membrane, GN - glomerulonephritis, GPA - granulomatosis with polyangiitis, GPS Goodpasture's syndrome, ICU - intensive care unit, IVIG - intravenous immunoglobulin, MCTD - mixed connective tissue disease, MPA - microscopic polyangiitis, MPO myeloperoxidase, NAC - N-acetylcystein, NO -nitric oxide, eNOS - endothelial nitric oxide synthase, iNOS - inducible nitric oxide synthase, PRS - pulmonary-renal syndrome, RA rheumatoid arthritis, siRNA - small interfering ribonucleic acids, ROS - reactive oxygen species, SLE - systemic lupus erythematosus, WG - Wegener's granulomatosis

\section{Author details}

\author{
N. Lukán
}

$4^{\text {th }}$ Internal Department Medical Faculty, Safarik University, Košice, Slovak Republic

\section{References}

[1] Segen JC., editor. Concise Dictionary of Modern Medicine. New York: McGraw-Hill Companies; 2002.

[2] Sanders JS, Rutgers A, Stegeman CA, Kallenberg CG. Pulmonary-renal syndrome with a focus on anti-GBM disease. Semin Respir Crit Care Med 2011;32(3):328-34. 
[3] Jennette JC, Falk RJ, Andrassy K, Bacon PA, Churg J, Gross WL, Hagen EC, Hoffman GS, Hunder GG, Kallenberg CG et al.Nomenclature of systemic vasculitides.Proposal of an international consensus conference. Arthritis Rheum 1994;37(2):187-192.

[4] Langford CA.Vasculitis. J Allergy Clin Immunol 2010;125(2)Suppl.2:S216-S225.

[5] Goodpasture EW.The significance of certain pulmonary lesions in relation to the aetiology of pneumonia. Am J Med Sci 1919;158:863-70.

[6] Smith W, Andrewes CH, Laidlaw PP.A virus obtained from influenza patients. Lancet 1933;2 (5732):66-68.

[7] Stanton MC, Tange JD. Goodpasture's syndrome (pulmonary haemorrhage associated with glomerulonephritis). Australas Ann Med 1958;7:132-44.

[8] Collins RD. Dr. Goodpasture: "I was not aware of such a connection between lung and kidney disease". Ann Diagn Pathol 2010;14(3):194-8.

[9] Lerner RA, Glassock RJ, Dixon FJ.The role of anti-glomerular basement membrane antibody in the pathogenesis of human glomerulonephritis. The Journal of experimental medicine 1967;126(6):989-1004.

[10] Lee RW, D'Cruz DP. Pulmonary renal vasculitis syndromes. Autoimmun Rev. 2010; 9 (10):657-60.

[11] Salant, DJ. Immunopathogenesis of crescentic glomerulonephritis and lung purpura. Kidney Int 1987; 32:408-425.

[12] Schwarz MI, Zamora MR, Hodges TN, Chan ED, Bowler RP, Tuder RM. Isolated pulmonary capillaritis and diffuse alveolar hemorrhage in rheumatoid arthritis and mixed connective tissue disease. Chest June 1998;113(6):1609-15.

[13] Jennette JC. Implications for pathogenesis of patterns of injury in small- and medium-sized vessel vasculitis. Cleve Clin J Med 2002;69(Suppl 2):SII33-38.

[14] Wegener F. Uber die eigenartige Rhinogene Granulomatose mit besonderer Beteiligung des Arteriensystems un der Nieren. Beitr Pathol Anat 1939;102:36-68.

[15] Former F. Uber die granulomatose Periglomerulitis. Schweiz Zeitschrift allgemeine Pathol Bakteriol 1950;13:42-59.

[16] Rutgers A, Slot M, van Paassen P, van Breda Vriesman P, Heeringa P, Tervaert JW. Coexistence of anti-glomerular basement membrane antibodies and myeloperoxidase-ANCAs in crescentic glomerulonephritis. Am J Kidney Dis 2005;46(2):253-62.

[17] Kambham N. Crescentic Glomerulonephritis: an update on Pauci-immune and AntiGBM diseases. Adv Anat Pathol 2012;19(2):111-24.

[18] Cordier JF, Cottin V. Alveolar hemorrhage in vasculitis: primary and secondary. Semin Respir Crit Care Med 2012;32(3):310-21. 
[19] Miller LR, Greenberg SD, McLarty JW. Lupus lung. Chest 1985;88(2):265-9.

[20] Jennette JC, Falk RJ.Vasculitis (Polyarteritis Nodosa, Microscopic Polyangitis, Wegener's Granulomatosis, Henoch-Schönlein Purpura). In: Schrier RW. (ed.): Atlas of Diseases of the Kidney. Systemic Diseases and the Kidney. Volume IV. New Jersey: Wiley\&Sons; 1999, pp. 22 - 34. Available from www.scribd.com/doc/70966728/Atlasof-Diseases-of-the-Kidney-Vol-IV.

[21] Alenzi FQ, Salem ML, Alenazi FA, Wyse RK. Cellular and molecular aspects of Goodpasture syndrome. Iran J Kidney Dis 2012;6(1):1-8.

[22] de Lind van Wijngaarden RA, van Rijn L, Hagen EC, Watts RA, Gregorini G, Tervaert JW, Mahr AD, Niles JL, de Heer E, Bruijn JA, Bajema IM. Hypotheses on the etiology of antineutrophil cytoplasmic autoantibody associated vasculitis: the cause is hidden, but the result is known. Clin J Am Soc Nephrol 2008;3(1):237-52.

[23] Ko GJ, Rabb H, Hassoun HT. Kidney-lung crosstalk in the critically ill patient. Blood Purif 2009;28(2):75-83.

[24] Singbartl K. Renal-pulmonary crosstalk. Contrib Nephrol 2011;174:65-70.

[25] Short AK, Esnault VL, Lockwood CM. Anti-neutrophil cytoplasm antibodies and anti-glomerular basement membrane antibodies: two coexisting distinct autoreactivities detectable in patients with rapidly progressive glomerulonephritis. Am J Kidney Dis 1995;26(3):439-45.

[26] Kalluri R, Meyers K, Mogyorosi A, Madaio MP, Neilson EG. Goodpasture syndrome involving overlap with Wegener's granulomatosis and anti-glomerular basement membrane disease. J Am Soc Nephrol 1997;8(11):1795-800.

[27] Thurman JM. Triggers of inflammation after renal ischemia/reperfusion. Clin Immunol 2007;123(1):7-13.

[28] McCabe C, Jones Q, Nikolopoulou A, Wathen C, Luqmani R. Pulmonary-renal syndromes: an update for respiratory physicians. Respir Med 2011;105(10):1413-1421.

[29] Gröne HJ. Vasculitis - aspect of cellular and molecular pathogenesis. (German) Verh Dtsch Ges Pathol 2001;85:142-52.

[30] Bajwa A, Kinsey GR, Okusa MD. Immune mechanisms and novel pharmacological therapies of acute kidney injury. Curr Drug Targets 2009;10(12):1196-204.

[31] Campanholle G, Landgraf RG, Gonçalves GM, Paiva VN, Martins JO, Wang PH, Monteiro RM, Silva RC, Cenedeze MA, Teixeira VP, Reis MA, Pacheco-Silva A, Jancar S, Camara NO. Lung inflammation is induced by renal ischemia and reperfusion injury as part of the systemic inflammatory syndrome. Inflamm Res 2010;59(10): $861-9$. 
[32] Groshaus HE, Manocha S, Walley KR, Russell JA. Mechanisms of beta-receptor stimulation induced improvement of acute lung injury and pulmonary edema. Crit Care 2004; 8(4): 234-42.

[33] Hamacher J, Stammberger U, Roux J, Kumar S, Yang G, Xiong C, Schmid RA, Fakin RM, Chakraborty T, Hossain HM, Pittet JF, Wendel A, Black SM, Lucas R. The lectinlike domain of tumor necrosis factor improves lung function after rat lung transplantation - potential role for a reduction in reactive oxygen species generation. Crit Care Med 2010;38(3):871-8.

[34] Yang G, Hamacher J, Gorshkov B, White R, Sridhar S, Verin A, Chakraborty T, Lucas R. The Dual Role of TNF in Pulmonary Edema. J Cardiovasc Dis Res 2010;1(1):29-36.

[35] Schoeb TR, Jarmi T, Hicks MJ, Henke S, Zarjou A, Suzuki H, Kramer P, Novak J, Agarwal A, Bullard DC. eNOS inhibits the development of autoimmune-mediated vasculitis. Arthritis Rheum. 2012 Aug 29. doi: 10.1002/art.37683. [Epub ahead of print].

[36] Wever R, Boer P, Hijmering M, Stroes E, Verhaar M, Kastelein J, Versluis K, Lagerwerf F, van Rijn H, Koomans H, Rabelink T. Nitric oxide production is reduced in patients with chronic renal failure. Arterioscler Thromb Vasc Biol 1999;19(5):1168-72.

[37] Vaziri ND, Ni Z, Oveisi F, Liang K, Pandian R. Enhanced nitric oxide inactivation and protein nitration by reactive oxygen species in renal insufficiency. Hypertension 2002;39(1):135-41.

[38] Druhan LJ, Forbes SP, Pope AJ, Chen CA, Zweier JL, Cardounel AJ. Regulation of eNOS derived superoxide by endogenous methylarginines. Biochemistry 2008;47(27): 7256-63.

[39] Eiserich JP, Hristova M, Cross CE, Jones AD, Freeman BA, Halliwell B, van der Vliet A. Formation of nitric oxide-derived inflammatory oxidants by myeloperoxidase in neutrophils. Nature 1998;391(6665):393-7.

[40] Weyand CM, Goronzy JJ. Pathogenic mechanisms in giant cell arteritis. Cleve Clin J Med 2002;69(Suppl 2):SII28-32.

[41] Bratt J, Palmblad J. Cytokine-induced neutrophil-mediated injury of human endothelial cells. J Immunol 1997;159(2):912-8.

[42] Guilpain P, Servettaz A, Batteux F, Guillevin L, Mouthon L. Natural and disease associated anti-myeloperoxidase (MPO) autoantibodies. Autoimmun Rev 2008;7(6): 421-5.

[43] Spapen H, Zhang H, Demanet C, Vleminckx W, Vincent JL, Huyghens L. Does Nacetyl-L-cysteine influence cytokine response during early human septic shock? Chest 1998;113(6):1616-24. 
[44] Park SJ, Pai KS, Kim JH, Shin JI. Beneficial effect of N-acetylcysteine on antineutrophil cytoplasmic antibody-associated vasculitis. J Rheumatol 2012;39(1):186.

[45] Shah SV, Baricos WH, Basci A. Degradation of human glomerular basement membrane by stimulated neutrophils. Activation of a metalloproteinase(s) by reactive oxygen metabolites. J Clin Invest 1987;79(1):25-31.

[46] Kalluri R, Cantley LG, Kerjaschki D, Neilson EG. Reactive oxygen species expose cryptic epitopes associated with autoimmune Goodpasture syndrome. J Biol Chem 2000;275(26):20027-32.

[47] Cohen IR, Cooke A. Natural autoantibodies might prevent autoimmune disease. Immunol Today 1986;7(12):363-364.

[48] Stegeman CA, Cohen-Tervaert JW, Sluiter WJ, Manson WL, de Jong PE, Kallenberg CGM. Association of chronic nasal carriage of staphylococcus aureus and higher relapse rates in Wegener granulomatosis. Ann Intern Med 1994;120(1):12-17.

[49] Boros P, Gondolesi G, Bromberg JS. High dose intravenous immunoglobulin treatment: mechanisms of action. Liver Transpl 2005;11(12):1469-1480.

[50] Sakaguchi S, Sakaguchi N, Asano M, Itoh M, Toda M. Immunologic self-tolerance maintained by activated T cells expressing IL-2 receptor alpha-chains (CD25). Breakdown of a single mechanism of self-tolerance causes various autoimmune diseases. J Immunol 1995;155(3):1151-64.

[51] Taams LS, Akbar AN. Peripheral generation and function of CD4+CD25+ regulatory T cells. Curr Top Microbiol Immunol 2005;293:115-31.

[52] Mills KH, McGuirk P. Antigen-specific regulatory T cells - their induction and role in infection. Semin Immunol 2004;16(2):107-17.

[53] Abdulahad WH, Stegeman CA, van der Geld YM, Doornbos-van der Meer B, Limburg PC, Kallenberg CG. Functional defect of circulating regulatory CD4+ T cells in patients with Wegener's granulomatosis in remission. Arthritis Rheum 2007;56(6): 2080-2091.

[54] Miossec P, Korn T, Kuchroo VK. Interleukin-17 and type 17 helper T cells. N Engl J Med 2009;361(9):888-898.

[55] Tadema H, Heeringa P, Kallenberg CG. Bacterial infections in Wegener's granulomatosis: mechanisms potentially involved in autoimmune pathogenesis. Curr Opin Rheumatol 2011;23(4):366-71.

[56] Sutton CE, Lalor SJ, Sweeney CM, Brereton CF, Lavelle EC, Mills KH. Interleukin-1 and IL 23 induce innate IL-17 production from gammadelta T cells, amplifying Th17 responses and autoimmunity. Immunity 2009;31(2):331-41.

[57] Ooi JD, Phoon RK, Holdsworth SR, Kitching AR. IL-23, not IL-12, directs autoimmunity to the Goodpasture antigen. J Am Soc Nephrol 2009;20(5):980-9. 
[58] Fouser LA, Wright JF, Dunussi-Joannopoulos K, Collins M: Th17 cytokines and their emerging roles in inflammation and autoimmunity. Immunol Rev 2008;226:87-102.

[59] Thadhani R, Pascual M, Bonventre JV.Acute renal failure. N Engl J Med 1996 ; 334:1448-1460.

[60] Niles JL et al. The syndrome of lung hemorrhage and nephritis is usually an ANCAassociated condition. Arch Intern Med 1996;156:440-445.

[61] Peters DK, Rees AJ, Lockwood CM, Pusey CD. Treatment and prognosis in antibasement membrane antibody-mediated nephritis. Transplant Proc 1982;14(3):513-21.

[62] Gaskin G, Pusey CD. Plasmapheresis in antineutrophil cytoplasmic antibody-associated systemic vasculitis. Ther Apher 2001;5(3):176-81.

[63] Levy JB, Turner AN, Rees AJ, Pusey CD. Long term outcome of anti-glomerular basement membrane antibody disease treated with plasma exchange and immunosuppression. Ann Intern Med 2001;134:1033-42.

[64] Griffiths M, Brett S. The pulmonary physician in critical care illustrative care 3: pulmonary vasculitis. Thorax 2003;58:543-6.

[65] Fernández-Fernández FJ, Sesma P. Acetylcysteine as adjuvant therapy for vasculitis associated with antineutrophil cytoplasmic antibody. J Rheumatol 2011;38(4):785.

[66] Demedts M, Behr J, Buhl R, Costabel U, Dekhuijzen R, Jansen HM, MacNee W, Thomeer M, Wallaert B, Laurent F, Nicholson AG, Verbeken EK, Verschakelen J, Flower CD, Capron F, Petruzzelli S, De Vuyst P, van den Bosch JM, Rodriguez-Becerra E, Corvasce G, Lankhorst I, Sardina M, Montanari M; IFIGENIA Study Group. Highdose acetylcysteine in idiopathic pulmonary fibrosis. N Engl J Med 2005;353(21): 2229-42.

[67] Lee JH, Jo YH, Kim K, Lee JH, Rim KP, Kwon WY, Suh GJ, Rhee JE. Effect of N acetylcysteine (NAC) on acute lung injury and acute kidney injury in hemorrhagic shock. Resuscitation 2012 Jun 1. [Epub ahead of print].

[68] Dharmapalaiah C, Watts RA. The role of biologics in treatment of ANCA-associated vasculitis. Mod Rheumatol 2012;3:319-26.

[69] Manzi S, Sánchez-Guerrero J, Merrill JT, Furie R, Gladman D, Navarra SV, Ginzler EM, D'Cruz DP, Doria A, Cooper S, Zhong ZJ, Hough D, Freimuth W, Petri MA; on behalf of the BLISS-52 and BLISS-76 Study Groups. Effects of belimumab, a B lymphocyte stimulator-specific inhibitor, on disease activity across multiple organ domains in patients with systemic lupus erythematosus: combined results from two phase III trials. Ann Rheum Dis 2012;71(11):1833-1838.

[70] Walsh GM, Reslizumab. A humanized anti-IL-5 mAb for the treatment of eosinophilmediated inflammatory conditions. Curr Opin Mol Ther 2009;11:329-36.

[71] Schmitt WH, Hagen EC, Neumann I, Nowack R, Flores-Suárez LF, Van der Woude FJ, European Vasculitis Study Gro up. Treatment of refractory Wegener's granuloma- 
tosis with antithymocyte globulin (ATG): an open study in 15 patients. Kidney Int 2004;65:1440-8.

[72] Podojil JR, Miller SD. Molecular mechanisms of T-cell receptor and costimulatory molecule ligation/blockade in autoimmune disease therapy. Immunol Rev 2009;229(1):337-55.

[73] Kälsch AI, Soboletzki M, Schmitt WH, van der Woude FJ, Hochhaus A, Yard BA, Birck R. Imatinib mesylate, a new kid on the block for the treatment of anti-neutrophil cytoplasmic autoantibodies-associated vasculitis? Clin Exp Immunol 2008;3:391-8.

[74] Bontscho J, Schreiber A, Manz RA, Schneider W, Luft FC, Kettritz R. Myeloperoxidase-specific plasma cell depletion by bortezomib protects from anti-neutrophil cytoplasmic autoantibodies-induced glomerulonephritis. J Am Soc Nephrol 2011;22(2): 336-48.

[75] Negi VS, Elluru S, Siberil S, Graff-Dubois S, Mouthon L, Kazatchkine MD, LacroixDesmazes S, Bayry J, Kaveri SV. Intravenous immunoglobulin: an update on the clinical use and mechanisms of action. J Clin Immunol 2007;27(3):233-245.

[76] Lapraik C, Watts R, Bacon P, Carruthers D, Chakravarty K, D'Cruz D, Guillevin L, Harper L, Jayne D, Luqmani R, Mooney J, Scott D.BSR and BHPR Standards, Guidelines and Audit Working Group. BSR and BHPR guidelines for the management of adults with ANCA associated vasculitis. Rheumatology (Oxford) 2007;46(10): 1615-1626.

[77] Leong H, Stachnik J, Bonk ME, Matuszewski KA.Unlabeled uses of intravenous immune globulin. Am J Health Syst Pharm 2008;65(19):1815-1824.

[78] Yu Z, Lennon VA.Mechanism of intravenous immune globulin therapy in antibodymediated autoimmune diseases. N Engl J Med 1999;340(3):227-228. 